\title{
STEM students' voluntary use of YouTube to learn science topics taught in high school and/or college
}

\author{
Raquib Khan, William W. Cobern, Betty Adams, and Joao R. Amadeu Filho \\ The Mallinson Institute for Science Education, Western Michigan University, Kalamazoo, MI, 49008
}

\begin{abstract}
Use of YouTube videos by STEM instructors is common. Many instructors suggest those videos to their students and sometimes require them to watch. However, little is known about students' voluntary use of YouTube videos to learn topics taught in their high school and/or college science courses. In this study, we surveyed 596 undergraduate, US college students of different majors, who took physics laboratory courses of different levels. Our findings are that many students do consult YouTube videos to learn about the physics topics they encounter in the classroom. We also found that this practice was much more prevalent amongst college students than amongst high school students. Further analysis of the data revealed some of the key reasons behind students' tendency towards and against voluntary use of YouTube videos to learn those topics.
\end{abstract}

\section{INTRODUCTION}

According to Amazon's "Alexa Traffic Ranks," YouTube, which allows free access to almost all of its content to any internet user, is the second most visited online platform in the world after Google. Much of its content is created and uploaded for the purpose of sharing scientific knowledge, which may be accessed, among others, by teachers and students of science, technology, engineering, and mathematics (STEM). Thus, the effects of teacher and student use of YouTube on STEM instruction and learning becomes a concern for the STEM education community. Research exists on instructor directed use of YouTube videos for science learning, such as when an instructor incorporates a YouTube video into a lesson he or she is presenting [1-5]. On the other hand, the literature is rather silent on students' voluntary use of YouTube videos in support of their science learning. Indeed, it is not even clear that this is a common student practice. However, given the characteristics of the "Net Generation," we believe it is important to ask: do students of STEM subjects voluntarily use YouTube to learn science topics? Our research investigated the extent to which students enrolled in college physics laboratory courses reported the voluntary use of YouTube videos as an aid to learning course related science objectives.

\section{LITERATURE REVIEW}

YouTube provides free access to almost all of its content. Any user can search YouTube for videos by using different key words. Uploading content on YouTube is also usually free of cost, if you register (usually free of cost) as a user on YouTube. This opportunity allows any internet user to create different content and upload on YouTube, which other users can watch at will. Many of these videos discuss different topics pertaining to science fields such as physics, chemistry, biology, mathematics, engineering, geology, astronomy, etc. Statistical data collected and shared by YouTube suggests that millions of people worldwide subscribe to different channels known for their video content on STEM topics, and hundreds of millions of people view those videos (see Table 1). Many of these topics are taught in high school and/or college level STEM courses. Hence, if they wish, high school and college students can have easy access to course relevant videos.

TABLE 1. List of several YouTube channels known popular for producing videos related to science topics.

\begin{tabular}{cccc}
\hline Channels & $\begin{array}{c}\text { Number } \\
\text { of } \\
\text { Videos }\end{array}$ & $\begin{array}{c}\text { Subscribers } \\
\text { (millions) }\end{array}$ & $\begin{array}{c}\text { Views } \\
\text { (millions) }\end{array}$ \\
\hline National & 8,790 & 8.4 & 2,500 \\
Geographic & 7,028 & 4.4 & 1,535 \\
Khan Academy & 370 & 13.3 & 1,435 \\
VSauce & 273 & 8 & 1,070 \\
AsapSCIENCE & 965 & 7.8 & 864 \\
CrashCourse & 82 & 6.4 & 432 \\
Kurzgesagt - & & 4.3 & 374 \\
In a Nutshell & 219 & 52.6 & 8,210 \\
MinutePhysics & 217,727 & 2018. & This \\
Total & 17
\end{tabular}

Note: Statistics updated in June, 2018. This table was collected from Rosenthal [6], p. 3, and then modified, and updated.

Considering the potential effect these videos can have on student STEM learning, it is important to know the extent to which students voluntarily turn to YouTube videos to learn course related, STEM topics. However, very little is known about the nature of the viewers of these videos, and if any of these viewers indeed receive help from these videos towards their learning of STEM topics. One may argue that the number of "likes" and "dislikes" for the videos provides an idea about the popularity of each video. But those numbers are not always reliable indicators of how viewers perceive of those videos [7]. In short, it is not known if high school and college students watch YouTube to help themselves learn STEM topics, and if they do, the extent of such use.

Rosenthal [6] comes closest to our interests. He studied public perception of "science" videos on YouTube. He 
surveyed 150 college, undergraduate communication students and 123 randomly chosen non-students. The sample chosen by Rosenthal represents non-STEM major students, many of who might have not taken STEM courses in high school or college. Therefore, the results of that study may not be generalized for students of STEM.

Rosenthal asked subjects how frequently they watch YouTube "science videos," however, he did not clarify in his survey or in his published report what he meant by "science video." Amadeu et al. [8] and Gustafsson [9] explain what YouTube "science videos" can look like. A science video could be a science project uploaded by a student, a video the classroom science lecture, or some form of science instructional video. Thus, when Rosenthal's subjects responded to his survey asking about science videos, we do not know how the subjects understood that term; however, Rosenthal's data does indicate that almost $90 \%$ of the student participants and $60 \%$ of the non-student participants reported to have watched YouTube science videos four days or more during the previous week.

Our research is much more focused. We are specifically interested in students going to YouTube for help with science courses either at high school or college. We do not say anything about types of videos, such as "science videos," but rather ask students if they ever voluntarily go to YouTube for help with respect to their science courses. Our research questions are:

RQ1a: To what extent do college students report the voluntary use of YouTube videos to help themselves learn science topics taught in high school science subjects, when they were in high school?

RQ1b: To what extent do college students report the voluntary use of YouTube videos to help themselves learn science topics taught in college science subjects?

RQ2a: Why do students who voluntarily watched YouTube videos to learn the topics covered by high school and/or college science courses do so?

RQ2b: Why do students who did not voluntarily watch YouTube videos to learn the topics covered by high school and/or college science courses did not do so?

\section{METHODOLOGY}

We addressed the research questions using a survey method. We developed the first version of our survey and piloted it with several non-science major students taking a lower level physics course. The student feedback and suggestions were used to refine the survey and develop the final form. The final version of the survey consisted of ten questions about participants' voluntary use of YouTube (six multiple-choice questions and four free-response questions), and eight demographic questions. We surveyed 596 undergraduate college students at a large, Midwest American public university. These students were enrolled in college physics laboratory classes in Spring, 2018; 56\% were enrolled in 1000 level courses while $42 \%$ were enrolled in 2000 level courses. Participants were predominantly male $(74 \%)$ and white $(77 \%)$; the remaining participants were African American (7\%), Asian (7\%), Hispanic (4\%). Remaining 5\% chose "other/prefer not to answer." As incentive, participants received bonus points towards the physics laboratory courses they were taking at the time the survey was conducted. The consent form attached to the survey deliberately excluded specific details about this study to prevent students from self-including into or self-excluding from participation. Quantitative data collected with the survey was transferred into a quantitative data analysis software. Responses of the open-ended questions were transcribed and cross-checked by two individual researchers to establish the reliability of the analysis of the data.

\section{RESULTS}

The survey asked the participants to think about the time they had spent in high school before coming to college and answer a few questions. Then the survey asked, "Did you ever voluntarily watch YouTube videos to learn any science topic required by those science courses?" The option choices to answer this question were a) all the time, b) often, c) rarely, and d) never. Participants were asked to pick one answer from those. 223 out of $596(38 \%)$ reported to have watched YouTube videos all the time or often to learn science taught in high school, while the remaining 473 reported to have rarely or never watched YouTube videos to learn the topics covered by high school science courses (see Figure 1).

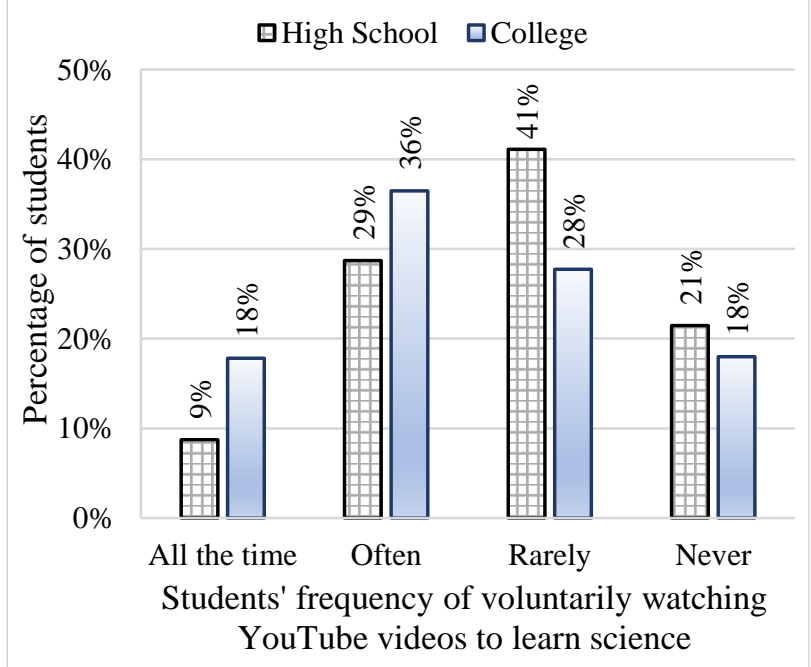

FIG 1. Frequency of students' self-reported usage of YouTube to learn science topics taught in high school and college.

Participants were then asked to think about the time they had spent in college and answer the same questions. 423 out of $596(54 \%)$ of the students reported to have "all 
the time" or "often" watched YouTube videos to learn the topics taught in college science courses, while the remaining 272 reported to have "rarely" or "never" watched YouTube videos to learn similar topics (see Figure 1).

Participants were then asked to provide reasons for their usage (or lack of usage) of YouTube videos to learn science topics. They could choose one or more of several potential reasons for and against voluntarily watching YouTube videos for science learning. Additional space was provided to the participants to add any additional reasons that were not listed as options. Interestingly, a whopping 422 out of 596 participants $(71 \%)$ selected "I did not understand the teacher's lecture on that topic(s)" as a reason for voluntarily turning to YouTube videos to learn science topics in their high school/college science courses. Moreover, 339 participants $(57 \%)$ chose "the textbook was not helpful enough to understand the topic(s)," and "being able to visualize complex concepts helps me learn faster and easier" as reasons behind their voluntary use of YouTube to learn science. Additionally, 149 participants (25\%) chose "I had missed the class in which that topic(s) was taught."

Analysis of data revealed that 213 participants out of the total $596(36 \%)$ reported to have rarely or never watched YouTube voluntarily to help themselves learn science topics. These participants were asked to respond to "If you never watched (or cannot remember if you watched) YouTube to learn any science topic required by the science courses in high school or college, please provide the reason why you never did so?" Analysis revealed that about $15 \%$ of that population stated that they were concerned about the accuracy of the content found in YouTube videos. 9\% of that population perceived using YouTube highly time-consuming, while the same percentage of those 213 participants reported that they never thought of YouTube as a potential source of help.

\section{DISCUSSION}

Despite a white and male dominated sample, the sample size was such that we achieved adequate statistical power (more than $80 \%$ at $p=0.05$ ) for transferring the results to similarly diverse group of students.

Findings of this study suggest that a majority of students at the college level voluntarily watch YouTube videos for help learning science taught in college level science courses (RQ1b). The proportion of the students who voluntarily watched YouTube videos during high school to learn science topics was also considerable (RQ1a). At the college level, engineering majors were the most frequent YouTube users. The slightly increased voluntary use of YouTube for college science learning over high school could come from students finding that they can benefit from YouTube to learn science topics. This finding is supported by many participant responses that they did not realize that YouTube was a potential resource for science learning. For example, one responder said, "In high school, I did not think about using YouTube to learn science." Hence, making high school students more aware of the potential resource that YouTube is for learning science may benefit their learning of science topics in high school.

Data obtained from the survey provided a good understanding of why many students voluntarily watch YouTube videos to learn science topics (RQ2a). A majority of the students who voluntarily watch YouTube videos very frequently to learn science topics appear to do so as result of not understanding their science instructors. Openended comments provided some explanations. For example, one response stated, "During class, all that was done were example problems, but [the instructor] rarely showed us how to do each problem. Learning was done outside of the lecture hall always," or "The notebook was not as helpful. I often missed lecture due to work. When I did attend, the professor briefly went over the topic and I wanted a more in-depth look to understand." Another said, "I didn't understand the lecture materials. Watching examples completed on videos helped tremendously," or "YouTube has taught me more than my professors. Professors sometimes will not explain enough of the topic, or just will not at all explain it." YouTube may give students authority of their own learning, as one of the participants said, "If the teacher's lecture was not sufficient, I would watch the videos to learn the material by myself. I never had the need to watch videos until I got to college and realized it is acceptable to have a $40 \%$ class average and not change your teaching style at all." Many students found the textbook too difficult to understand and hence, turned to YouTube to learn those topics. Some were genuinely interested in the science, and hence wanted to learn more. One of the responses depicts the student's affective aspect of learning very well: "Science is my favorite subject. I have an endless passion to explore the world of science. Chemistry, biology and physics are my most favorite science subjects. I started falling in love with science since I was a child. This passion will never go away." Some of the participants deemed different ways to approach to a new topic very effective. Some quotes provide further insight. "I watch YouTube videos right after class in the library to help me better understand a topic right away after learning a new topic for the first time." Another said, "The visual/auditory combo is extremely helpful in topics like chemistry and physics."

Based on the findings from the analysis of the data, students who rarely voluntarily watched YouTube to learn science did not turn to YouTube for several reasons (RQ2b). It appears that many students did not realize that YouTube could be a potential resource to learn science. This notion was particularly prevalent among students who did not often use YouTube videos to learn topics of science taught in high school. One student stated, "In high school, 
I did not think about using YouTube.” Many students were concerned about the accuracy of the content available in YouTube. For example, one student stated, "Initially, I was concerned about the accuracy of the video." Another said, "I try to rely on the resources provided by and/or suggested by the professor so that I know the information is relevant and accurate." One of the more frequent reasons students gave for not using YouTube to learn science at high school was the lack of access to YouTube. One student stated, "In high school, I did not have Wi-Fi." A similar response read, "At home, YouTube doesn't work on the slow connection." Another said, "YouTube was sometimes not available to me."

Free response questions encouraged students to share their motivations behind their voluntary use of YouTube videos to learn science. Overall analysis of such reasons which came up from these free response questions indicate that students resort to YouTube videos as a means of learning when the traditional means of learning such as lectures and textbooks are not helpful enough. Students who genuinely enjoy learning science seem to voluntarily watch YouTube videos even if the traditional means of learning such as instructors' lectures and textbooks are helpful. Many of the students who did not often use YouTube either did not have access to YouTube, did not recognize YouTube as a potential resource to learn science, were concerned about the relevance and accuracy of the content found in YouTube, or did not bother searching YouTube simply because they did not enjoy science.

Reflecting on the original research questions, this study provides insight on the extent to which college students report voluntarily using YouTube to learn science taught in high school (RQ1a) and college (RQ1b). Some students reported using YouTube, while at high school for help learning the science taught in high school science courses; however, a majority did not. Many students reported lacking access to YouTube during high school or the ease of science taught in high school as the reasons for their nonuse of YouTube (RQ2b). The pattern of voluntarily using YouTube to learn science seems more prevalent among students at college than in high school. Many students reported often resorting to YouTube to learn science taught in college because they found YouTube to be a strong learning resource, especially when traditional learning resources such as lectures and textbooks were not helpful enough. Other students who enjoy learning science voluntarily use YouTube regardless of the effectiveness of the traditional learning resources such as lectures and textbooks (RQ2a). Students who do not resort to YouTube for help learning their college science courses are primarily concerned about the accuracy of YouTube content. Others cite a lack of enjoyment in science and desire to learn science.

Since many students seem to be unaware of the potential of YouTube as a science learning resource, instructors of both high schools and colleges may explicitly mention in their class how YouTube can be used as a science learning resource besides the lectures and textbooks available to them. This practice does not have to contradict with instructors' individual style of instruction so that students will be aware of the availability of YouTube towards better learning science topics taught both in high school and science, but not require them to use those videos. Nonetheless, many students stated in the free response questions that they never had to resort to YouTube because the lectures and the textbooks were effective enough. This is a strong message to science instructors on the importance of improving the effectiveness of their instruction so that students do not have to resort to YouTube. Many students stated their concern about the ease of availability of relevant topics on YouTube and its accuracy. Thus, science education researchers may focus future research on the relevance and accuracy of science content of YouTube on different topics taught in high school and/or college. Moreover, research may be focused on the effectiveness of YouTube videos as a science learning resource compared to traditional resources such as lectures, textbooks, and notebooks.

[1] C. K. Chan, Education and Teaching Int., 52(5), 474484 (2015).

[2] Y. Chtouki et al., Info Tech. Based Higher Ed. and Training Int Conf. 1-4 (2012).

[3] C.J. Erick et al., College Science Teaching, 42(1), 26 (2012).

[4] D. Y. Lee et al., Computers \& Education, 61, 193-208 (2013).

[5] S. Roodt et al., Informing Sc. \& Info. Tech. Ed. Conf., 473-488 (2013).

[6] S. Rosenthal, Int. J. of Sc. Ed., B, 1-18 (2017).

[7] C.S. Lee et al., Online Info. Rev., 41(5), 611-625 (2017).

[8] J. R. A. Filho, W. W. Cobern, B. Adams, and R. Khan, accepted for poster presentation at PERC 2018.

[9] P. Gustafsson, Ed. Res. For Social Change, 2(1), 117129 (2013) 